\title{
Comparison of Different Volumes of Local Anaesthetic to Determine Optimal Volume to Be Used In TAP Block For Post Caesarean Section Analgesia
}

\author{
Shraddha Malik', Sunny Malik', Wahaja Karim ${ }^{3}$, Reena Chabda ${ }^{4}$ \\ ${ }^{1}$ Assistant Professor, Rajiv Gandhi Super Specialty Hospital, Tahirpur, New Delhi, ${ }^{2}$ Consultant, Rajiv Gandhi Cancer Institute, Niti Bagh, South Delhi, \\ ${ }^{3}$ Assisstant Professor, VMMC \& Safdarganj Hospital, New Delhi, ${ }^{4}$ Senior Resident, Ram Manohar Lohiya Hospital, New Delhi.
}

\section{Abstract}

Background: The transverse abdominis plane (TAP) block, provides effective analgesia after lower abdominal surgeries if used as part of multimodal analgesia. In this prospective, randomized double-blind study, we proposed to determine the optimal volume of local anaesthetic to be used in ultrasound guided TAP (transversus abdominis plane) block for post Caesarean section analgesia. Subjects and Methods: Total 90 parturients were randomly allocated to group A, group B and group C to receive after routine spinal anaesthesia, bilateral TAP blocks with $15 \mathrm{ml}, 20 \mathrm{ml}$ and $30 \mathrm{ml}$ of $0.2 \%$ Ropivacaine in addition to standard analgesic comprising intravenous(IV) Acetaminophen, 1 gram 8 hourly and IV patient-controlled analgesia (PCA) with fentanyl. Each patient was assessed at 0.5, 2, 4, 6, 8, 10, 12, and 24 hours after surgery by an independent observer for pain at rest and on movement using visual analog scale, time of 1st demand for fentanyl, total consumption of PCA fentanyl, satisfaction with pain management and side effects(nausea, vomitng and sedation). Results: Use of fentanyl was significantly reduced in group B and C compared to Group A during $24 \mathrm{~h}$ after surgery $(\mathrm{P}<0.001)$. Pain scores were lower both on rest and activity at each time point for $24 \mathrm{~h}$ in groups $\mathrm{B}$ and $\mathrm{C}(\mathrm{P}<0.001)$, time of first analgesia was significantly longer, satisfaction was higher, and side effects were less in group B and C compared to group A. The difference was not significant between group B and C. Conclusion: We concluded that though increasing the volume of local anaesthetic from $15 \mathrm{ml}$ bilaterally to $20 \mathrm{ml}$ bilaterally resulted in increased duration and quality of analgesia, further increase to $30 \mathrm{ml}$ bilaterally offered no significant advantage in terms of reduction in VAS scores or opioid consumption.

Keywords: Ropivacaine, Cesarean section, Transverse abdominis plane block, Patient controlled analgesia, Opioids.

Corresponding Author: Dr. Shraddha Malik, Assistant Professor, Rajiv Gandhi Super Specialty Hospital, Tahirpur, New Delhi.

Received: October 2019

Accepted: October 2019

\section{Introduction}

Effective relief of post operative pain following Caesarean section is a challenge as mothers are expected to nurse and care for the new born in the immediate post operative period and motivated women want to be alert ,comfortable and mobile.Pain after cesarean section is usually described as moderate to severe by most patients and failure to adequately treat it may affect mother-baby bonding, care of newborn, and breastfeeding. ${ }^{[1]}$ It may even risk the patients for thrombo-embolism as a result of immobility due to pain. ${ }^{[2]}$ The pain management should not only be adequate but also safe for the breastfeeding baby. Pain of cesarean section essentially has two components - somatic (due to abdominal wall incision) and visceral (from the uterus) and a substantial component of pain is derived from abdominal wall incision. ${ }^{[3]}$

Systemic or neuraxial opioids are the mainstay for treating postoperative pain, as they are effective against both the components. However, they are associated with a number of undesirable side effects such as nausea, vomiting, sedation and respiratory depression. ${ }^{[4,5]}$

The Transversus abdominis plane (TAP) block, targets abdominal wall neural afferents between T6 and L1 and thus can relieve pain associated with an abdominal incision. 6 TAP is a neurovascular plane located between the internal oblique and transversus abdominis muscles and nerves supplying abdominal wall pass through this plane before supplying anterior abdominal wall. ${ }^{8}$ Therefore, if the local anesthetic is deposited in this space, myo-cutaneous sensory blockade results. ${ }^{[6,7]}$ Although there are very few reports of complications with TAP block, local anaesthetic toxicity remains a possibility, as large volumes are required for performing the block, especially when done bilaterally. Increasing the local anaesthetic concentration usually prolongs the duration of the nerve blocks, but TAP block is an exception as it relies on local anaesthetic spread, rather than concentration and hence is volume dependant. ${ }^{[9]}$ In pregnant populations, reduced plasma protein binding, increased cardiac output and blood flow, along with heightened neuronal sensitivity can result in potentially neurotoxic concentrations of local anaesthetic. ${ }^{[10]}$ Studies 
have reported toxic plasma concentrations for Ropivacaine at doses of $2.5 \mathrm{mg} / \mathrm{kg} .{ }^{10,11]}$ Seizures have occurred in pregnant patients at doses much below those conventionally used in non pregnant patients. ${ }^{[12,13]}$ Keeping these findings in mind we used $0.2 \%$ Ropivacaine, which enabled us to administer upto $30 \mathrm{ml}$ drug bilaterally without exceeding a dose of $2 \mathrm{mg} / \mathrm{kg}$ in any patient. Currently, there are no specific guidelines regarding the optimal procedure specific volumes and local anaesthetic concentrations to be used for TAP block. So the drug and volume should be chosen with caution especially for caesarean section.

As advised by the American Society of Regional Anaesthesia, a regional technique should be tailored to the minimum mass of local anaesthetic molecules necessary to achieve the desired clinical effect. Our study aims to compare different volumes of Ropivacaine, and thereby determine the optimum volume of local anaesthetic to be used in TAP block, without compromising the analgesic efficacy.

\section{Subjects and Methods}

The study had approval of our institutional review board and was conducted according to the study protocol approved by the board. After informed written consent, 90 adult parturients belonging to American Society of Anesthesiologists physical status I and II requiring elective or nonurgent cesarean (where no fetal or maternal compromise existed) via Pfannenstiel incision were recruited in this prospective double-blind study. Patients of $<50 \mathrm{~kg}$ or $>100 \mathrm{~kg}$ weight, with any contraindication to spinal anesthesia ,those with known hypersensitivity to drugs used, who were unable to understand visual analog scale(VAS) or use patient-controlled analgesia (PCA) were excluded from the study.

The recruited patients were randomly assigned to one of the three groups on the basis of computer-generated random number table. Allocation concealment was done by serially numbered opaque sealed envelopes (SNOSE) technique. These envelopes were opened on the day of surgery by a person not involved in the study. All patients received intravenous (IV) ranitidine $(50 \mathrm{mg}$ ) and metoclopramide (10 $\mathrm{mg}$ ) 20-30 min before transferring to OT as institutional protocol. Patients were given spinal anesthesia with 2-2.2 ml of $0.5 \%$ heavy bupivacaine and $15 \mathrm{mcg}$ of fentanyl at L3-5 level in sitting position, simultaneously coloading with 500 $\mathrm{ml}$ of Ringers lactate. Intra-operative antiemetics were not used routinely, but if needed, $4 \mathrm{mg}$ of ondansetron IV was used.

At the end of surgery, all patients received ultrasound guided bilateral TAP block in the mid axillary line. Using aseptic technique (gown, gloves, face mask and protective sheath for ultrasound probe) a high-frequency linear ultrasound probe(6-13 MHz, Sonosite MTurbo) was placed in transverse plane midway between the iliac crest and the subcostal margin in the mid axillary line. The fascial plane between the internal oblique and the transversus abdominis muscle was identified. A 21 gauge $100 \mathrm{~mm}$ needle attached by flexible tubing to a syringe filled with saline was used to perform the block.The needle was inserted anteriorly in plane along the line of ultrasound and guided towards the transversus abdominis plane. The final position of the probe was to be no further anterior than the anterior axillary line. Hydrodissection was performed using test injection of $3-5$ $\mathrm{ml}$ normal saline. After aspiration to exclude inadvertent vascular puncture, a test dose of 1-2 $\mathrm{ml}$ of the drug was injected to confirm needle placement. After a negative test dose, the study solution was injected while closely observing for signs of toxicity (tinnitus, perioral numbness, metallic taste in mouth, slurring of speech and mental status changes). TAP block was performed in a similar fashion on the opposite side.

All the patients were shifted to postanesthetic care unit (PACU) where they were observed for 1 hour, after which they were shifted to routine post delivery ward. The patients received standard analgesia according to obstetric department protocol consisting of IV Acetaminophen 1 gram 8 hourly, first dose was given at the end of surgery. In addition, they also received IV fentanyl through PCA $(10 \mathrm{mcg} / \mathrm{ml})$ set at $25 \mathrm{mcg}$ bolus dose, with $15 \mathrm{~min}$ lockout interval and $1 \mathrm{~h}$ limit of $100 \mathrm{mcg}$.

The assessment of presence and intensity of pain (both on rest and on passive flexion of hip and knee), nausea, vomiting, and sedation was done immediately after transfer to PACU $(0 \mathrm{~h})$ and at $0.5,2,4,6,8,10,12$ and $24 \mathrm{~h}$ after surgery. The intensity of pain was assessed on VAS $(0=$ no pain, and $10=$ worst pain). Rescue analgesia (in the form of Inj Diclofenac $75 \mathrm{mg}$ IV ) was given when VAS was $>4$ or patients self administered it via PCA pump.

Nausea and vomiting was assessed on a categorical PONV scoring scale $(0=$ no symptoms, $1=$ only nausea, $2=$ nausea and/vomiting only once, 3 = vomiting 2 or more times). $4 \mathrm{mg}$ ondansteron was given IV if patients complained of persistent nausea or vomited. Subjects requiring $\geq 2$ doses were given ondansetron round the clock ( $4 \mathrm{mg}$ thrice daily). Level of sedation was assessed using a simple AVPU scale of $0-3$, where $\mathrm{A} / 0=$ awake and alert, $\mathrm{V} / 1=$ quietly awake, $\mathrm{P} / 2$ = asleep but easily arousable, $\mathrm{U} / 3=$ deep sleep, responding to painful stimulus. Patients were labeled to be sedated if score was $>2$. Naloxone $(1-2 \mathrm{mcg} / \mathrm{kg})$ IV was administered if the score $\geq 3$.

The patients were also interviewed after $24 \mathrm{~h}$ of surgery regarding satisfaction with their pain management Likert scale. The scale included 5 Likert items: Very dissatisfied = 1 , dissatisfied $=2$, unsure $=3$, satisfied $=4$ and very satisfied $=5$. Patients were asked to verbally dictate the score of the satisfaction scale.

In PACU, all observations were made by an independent observer who was unaware of group allocation. The primary outcome was $24 \mathrm{~h}$ fentanyl consumption, and secondary outcome measures were pain scores at rest and movement, time of first analgesia, side effects(nausea, vomiting and sedation), and satisfaction with pain management. Time of first PCA fentanyl and cumulative fentanyl consumption at 2, $4,6,8,10,12$ and $24 \mathrm{~h}$ was obtained from electronic memory of PCA device.Any local complications of TAP block and number of doses of antiemetics and rescue analgesics administered were noted. Respiratory rate was the primary measure of safety. Clinically significant respiratory depression (respiratory rate less than 8 for $1 \mathrm{~min}$ ) was treated by ensuring patent airway and providing supportive 
treatment. If 2 such episodes occurred patient was withdrawn from study.

With reference to previous studies, a sample size of 30 per group was calculated based on a difference of 50 in total fentanyl consumed in 24 hours between any two Group A, Group B and Group C, with a SD of 50, at two-sided alpha of 0.05 , and a power of $90 \%$.

Statistical analysis was performed by the SPSS program for Windows, version 17.0 .Continuous variables are presented as mean $\pm \mathrm{SD}$, and categorical variables are presented as absolute numbers and percentage. Data were checked for normality before statistical analysis using Shaipro Wilk test. Normally distributed continuous variables were compared using ANOVA. If the $\mathrm{F}$ value was significant and variance was homogeneous, Bonferroni multiple comparison test was used to assess the differences between the individual groups; otherwise, Tamhane's T2 test was used. Categorical variables were analyzed using the chi square test. For all statistical tests, $\mathrm{p}$ value less than 0.05 was taken to indicate a significant difference.

\section{Results}

A total of 90 parturients who fulfilled the criteria were randomized for this study, 30 in each group. The groups were not different regarding demographic and other data as well as baseline hemodynamic parameters [Table 1].

\begin{tabular}{|l|l|l|l|l|}
\hline Table 1: Demographic data $($ mean \pm sd) \\
\begin{tabular}{|l} 
Demographic \\
Variables
\end{tabular} & Group A & Group B & Group C & $\begin{array}{l}\text { P } \\
\text { Value }\end{array}$ \\
\cline { 2 - 4 } & & & & \\
\hline Age & $28.73 \pm 2.02$ & $29.27 \pm 1.95$ & $29.10 \pm 1.84$ & 0.554 \\
\hline Weight & $64.70 \pm 3.03$ & $65.93 \pm 2.84$ & $66.10 \pm 2.56$ & 0.116 \\
\hline Height & $161.50 \pm 3.09$ & $161.53 \pm 2.73$ & $162.83 \pm 2.97$ & 0.140 \\
\hline BMI & $24.81 \pm 1.04$ & $25.29 \pm 1.39$ & $24.95 \pm 1.21$ & 0.297 \\
\hline
\end{tabular}

Mean fentanyl consumption within first $4 \mathrm{~h}$ of surgery was similar in both groups but subsequently total fentanyl consumed over first 24 hours was significantly less in group $\mathrm{B}$ and $\mathrm{C}$ in relation to group $\mathrm{A}(337.5+/-41.91$ and 315.83 +/- 46.84 in groups B and C respectively vs $485.02+/-35.11$ in group A). The difference between groups B and $\mathrm{C}$ was not statistically significant. [Figure 1].

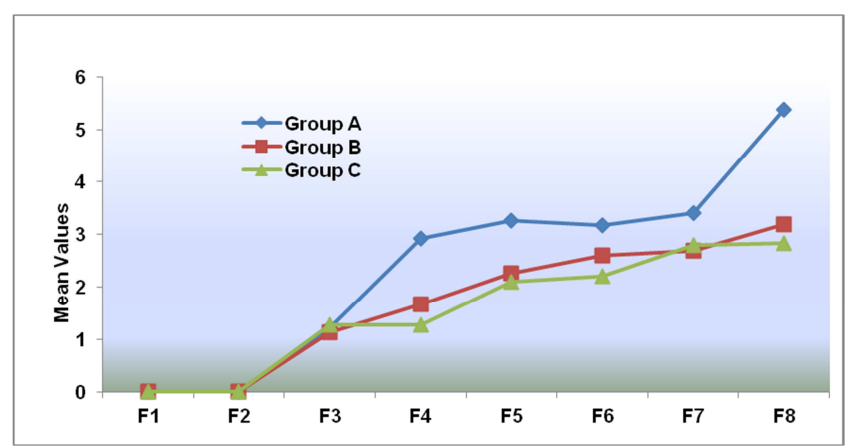

Figure 1:

The VAS for pain is depicted in Figure 2 and 3
The VAS scores were similar on arrival in PACU in both groups but were significantly lower at all-time points up to $24 \mathrm{~h}$ in group B and group $\mathrm{C}$ compared to group $\mathrm{A}$, both at rest and on movement $(\mathrm{P}<0.0001)$. Although the scores at 24 hours were lower in group $\mathrm{B}$, it was not statistically significant.

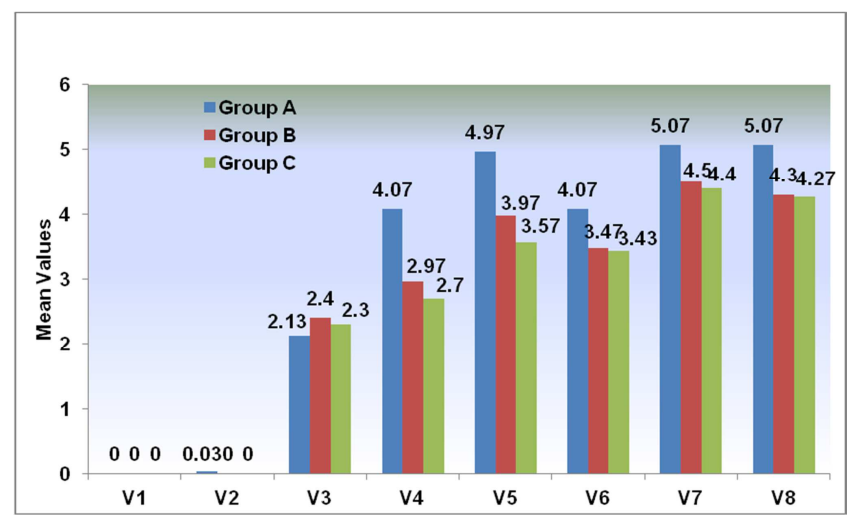

Figure 2:

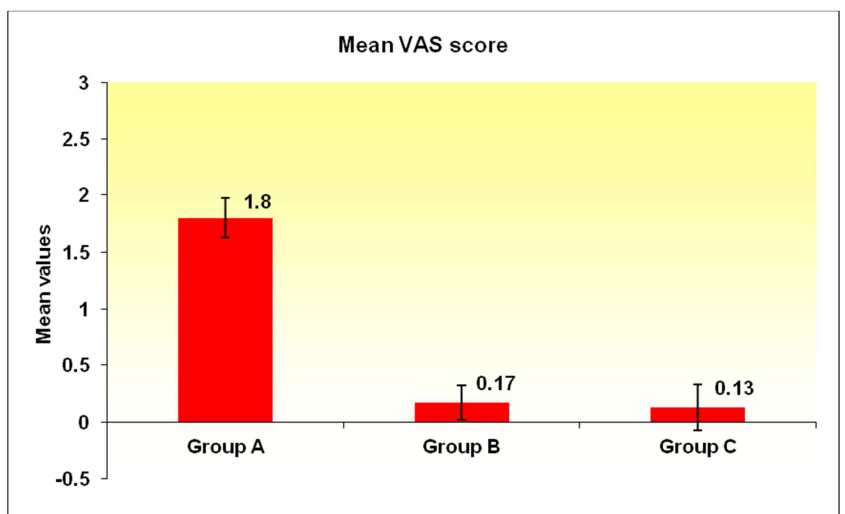

Figure 3:

Where none of the patients in group $\mathrm{B}$ and $\mathrm{C}$ were found sedated at any time, in group A $6.7 \%$ patients at $10 \mathrm{~h}, 13.3$ $\%$ patients at $12 \mathrm{~h}$ were found sedated. Postoperative nausea and vomiting (PONV) was more frequently noted in group B and $\mathrm{C}$ compared to group A. $46.7 \%$ of patients in group A required anti emetics and the cumulative PONV score for group A was also significantly higher than for group B and C (1.8 vs 0.17 and 0.13 respectively). Satisfaction with pain relief was significantly higher in group B and C. $70 \%$ pf patients in group A had disturbed sleep, only $16.7 \%$ patients in group B and $10 \%$ in group $\mathrm{C}$ reported sleep disturbance.

\section{Discussion}

Effective relief of Post-operative pain following caesarean section is challenging. The traditional opioids as a part of multimodal analgesia are difficult to administer because motivated women want to be alert, comfortable and mobile after caesarean section in order to care for their baby. ${ }^{[4]}$ So we used TAP block, a relatively new regional anaesthesia technique described first in 2001 by Rafi et $\mathrm{al}^{[6]}$, as an adjuvant to neuraxial blockade used for CS. Over recent years, there has been growing interest in regional nerve block 
techniques with promising results on efficacy, as they reduce the need of supplemental analgesia thereby lowering the incidence of drug-related side effects ${ }^{[14-16]}$

Our prospective randomised double blind study, conducted on 90 patients was aimed at comparing the analgesic efficacy of three different volumes of local anaesthetic $15 \mathrm{ml}, 20 \mathrm{ml}$ and $30 \mathrm{ml}$ each side of $0.2 \%$ Ropivacaine, to determine the optimal volume to be used in post-CS patients, in terms of reduction of VAS scores, opioid consumption and opioid related side-effects.

As described by Mukhtar K, TAP block is a type of abdominal field block, that relies on local anaesthetic spread rather than concentration; which signifies its volume dependency. ${ }^{[17]}$ But what is the actual volume needed is still debatable. TAP is a relatively new abdominal field block with excellent efficacy after a variety of abdominal surgeries including caesarean section. ${ }^{[15,18-21]}$ Previous placebocontrolled studies have shown clear analgesic benefit of TAP block in patients of cesarean delivery both under spinal $^{[4],[15,20,21]}$ and general anesthesia. Eslamian et al. ${ }^{[22]}$ and Tan et al. ${ }^{5}$ evaluated efficacy of TAP block versus no block in patients undergoing cesarean delivery under general anesthesia. Patients in TAP group had lower VAS pain scores at rest and during coughing, utilized less PCA tramadol and had a longer time to ask for first analgesia, than the patients who did not receive block. The safety and efficacy can be further improved by use of ultrasound. The analgesic efficacy of US-guided TAP block has been proved by Niraj et al in abdominal surgeries. But he proposed that further research should be done to investigate whether it might be more efficient than IV-PCA and what effects can be drawn by the combination of both. ${ }^{[18]}$ Maitreyi et al. ${ }^{[23]}$ used $15 \mathrm{ml}$ of $0.5 \%$ Ropivacaine for US guided TAP block in patients undergoing caesarean section under spinal anesthesia. They found that TAP block with ropivacaine compared with normal saline reduced postoperative VAS at $24 \mathrm{~h}(\mathrm{P}=0.004918)$. Time for rescue analgesia in the study group was prolonged from 4.1 to $9.53 \mathrm{~h}(\mathrm{P}=0.01631)$. Mean requirement of tramadol in the first $24 \mathrm{~h}$ was reduced in the study group.

A recent systematic review and meta-analysis ${ }^{[24]}$ reviewed five randomized double-blind studies including 312 parturients receiving TAP block for management of pain after cesarean delivery. Out of five, two studies ${ }^{[25,26]}$ used intrathecal morphine along with bupivacaine for spinal anesthesia while others used plain bupivacaine. ${ }^{[4,15,20]}$ The conclusion was that TAP block was effective in reducing pain scores and morphine consumption for $24 \mathrm{~h}$ compared to the placebo group. But in patients where morphine was used as adjuvant to subarachnoid bupivacaine, the TAP block did not provide additional analgesic benefit. ${ }^{[26]}$ Two similar studies were conducted in ASA I and II patients undergoing elective caesarean section under spinal anaesthesia using 20 $\mathrm{ml}$ of $0.25 \%$ bupivacaine or levobupivacaine. The studies revealed that pain scores were lower and time of demand for first analgesia was significantly longer in study groups compared to control (no drug) groups. ${ }^{[27,28]}$ Another study conducted using $20 \mathrm{ml}$ of $0.375 \%$ ropivacaine on either side, which included ASA II patients undergoing caesarean section under spinal anesthesia; showed reduction in mean VAS score $(\mathrm{P}<0.001)$ and opioid requirement. ${ }^{[29]}$
Although opioids still play a central role in post CS pain management, they alone are not adequate and inadequate post-operative analgesia is one of the most common causes for poor patient satisfaction following Caesarean delivery. Some authors have claimed improved maternal satisfaction with opioid based IV-PCA, but the high incidence of associated adverse effects such as nausea/vomiting, pruritus, sedation and respiratory depression not only limit their use but also lower the patient satisfaction with pain relief. ${ }^{[30]} \mathrm{We}$ used TAP block as adjuvant to regular IV-PCA, in an attempt to reduce the total opioid requirement and the associated side effects. We chose fentanyl as it is a potent and safe opioid, with a much greater therapeutic index than morphine and is associated with less nausea, vomiting and pruritus compared to other opioids. ${ }^{[31]} \mathrm{We}$ found a statistically significant reduction in the total number of fentanyl boluses needed in Group B $(13.5 \pm 1.65)$ and Group C (12.6 \pm 1.47$)$ compared to Group A (19.4 \pm 1.40$)$, as shown in Figure 4. As depicted in Table 2; the total fentanyl (in micrograms) consumed over 24 hours in Group A was 485.02 \pm 35.11 which was significantly higher than in Group B and Group C (337.5 \pm 41.91 and $315.83 \pm 46.84$ ). The opioid sparing effect of TAP block in our study was established by the reduction of total fentanyl dose thus contributing to improvement in PONV score, sedation score and maternal satisfaction.

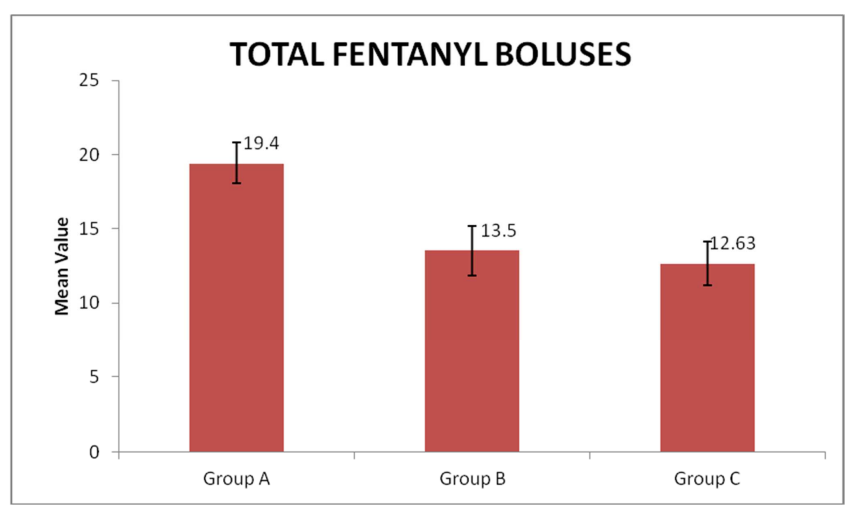

Figure 4:

Table 2:
\begin{tabular}{|l|l|l|l|l|l|l|}
\hline $\begin{array}{l}\text { Total } \\
\text { Fentanyl } \\
\text { Dose }\end{array}$ & $\begin{array}{l}\text { Mean } \pm \\
\text { SD }\end{array}$ & $\begin{array}{l}\text { Min - } \\
\text { Max }\end{array}$ & $\begin{array}{l}\text { P } \\
\text { Value }\end{array}$ & $\begin{array}{l}\text { Group } \\
\text { A } \\
\text { vs } \\
\text { Group } \\
\text { B }\end{array}$ & $\begin{array}{l}\text { Group } \\
\text { As } \\
\text { vs } \\
\text { Group } \\
\text { C }\end{array}$ & $\begin{array}{l}\text { Group } \\
\text { B } \\
\text { vs } \\
\text { Group } \\
\text { C }\end{array}$ \\
\hline $\begin{array}{l}\text { Group } \\
\text { A }\end{array}$ & $\begin{array}{l}485.02 \pm \\
35.11\end{array}$ & $400-575$ & $<0.001$ & $<0.001$ & $<0.001$ & 0.064 \\
\cline { 1 - 2 } $\begin{array}{l}\text { Group } \\
\text { B }\end{array}$ & $\begin{array}{l}337.5 \pm \\
41.91\end{array}$ & $275-425$ & & & & \\
\cline { 1 - 2 } $\begin{array}{l}\text { Group } \\
\text { C }\end{array}$ & $\begin{array}{l}315.83 \pm \\
46.84\end{array}$ & $250-400$ & & & & \\
\hline
\end{tabular}

Post-CS patients show an increased pain intensity due to raised anxiety in the mother and inter-individual variability in the perception of pain. ${ }^{[30]}$ As per our hospital protocol, we gave IV Acetaminophen at 8 hourly intervals to all the patients and a bolus of IV Diclofenac $75 \mathrm{mg}$ in the form of rescue analgesic when the VAS score was $>4$. In our study, a significant number i.e. $86.7 \%$ of patients in group A required 
rescue analgesic three times within 24 hours, whereas in Group $\mathrm{B}$ and $\mathrm{C}$, most patients $(76.7 \%$ and $86.7 \%$ respectively) required rescue analgesic only once as shown in Table 3, Figure 5. It was probably due to better quality of analgesia with $20 \mathrm{ml}$ and $30 \mathrm{ml}$ of Ropivacaine in TAP block in comparision to $15 \mathrm{ml}$. The difference between Groups B and $\mathrm{C}$ was not significant.

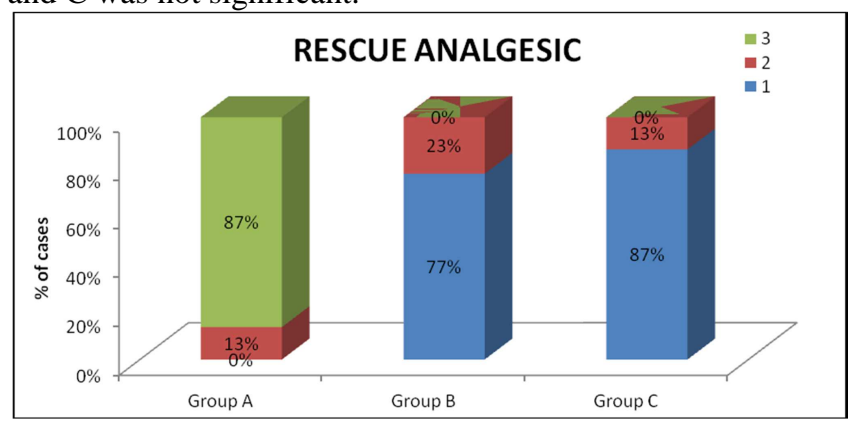

Figure 5:

\begin{tabular}{|c|c|c|c|c|c|c|c|}
\hline \multicolumn{8}{|c|}{ Table 3: } \\
\hline \multirow[t]{2}{*}{\begin{tabular}{|l} 
Rescue \\
Analgesic
\end{tabular}} & Group A & $\begin{array}{l}\text { Group } \\
\text { B }\end{array}$ & $\begin{array}{l}\text { Group } \\
\mathrm{C}\end{array}$ & \multirow[t]{2}{*}{$\begin{array}{l}\mathrm{P} \\
\text { value }\end{array}$} & \multirow{2}{*}{\begin{tabular}{|l} 
Group \\
A \\
vs \\
Group \\
B \\
\end{tabular}} & \multirow{2}{*}{\begin{tabular}{|l|} 
Group \\
A \\
vs \\
Group \\
C \\
\end{tabular}} & \multirow{2}{*}{$\begin{array}{l}\text { Group } \\
\text { B } \\
\text { vs } \\
\text { Group } \\
\text { C }\end{array}$} \\
\hline & $\mathrm{n}(\%)$ & $\mathrm{n}(\%)$ & $\mathrm{n}(\%)$ & & & & \\
\hline 1 & $0(0.0 \%)$ & $\begin{array}{l}23 \\
(76.7 \\
\%)\end{array}$ & $\begin{array}{l}26 \\
(86.7 \\
\%)\end{array}$ & $<0.001$ & $<0.001$ & $<0.001$ & 0.506 \\
\hline 2 & $\begin{array}{l}4 \\
(13.3 \%)\end{array}$ & $\begin{array}{l}7 \\
(23.3 \\
\%)\end{array}$ & $\begin{array}{l}4 \\
(13.3 \\
\%)\end{array}$ & & & & \\
\hline 3 & $\begin{array}{l}26 \\
(86.7 \%)\end{array}$ & $\begin{array}{l}0 \\
(0.0 \% \\
)\end{array}$ & $\begin{array}{l}0 \\
(0.0 \% \\
)\end{array}$ & & & & \\
\hline Total & $\begin{array}{l}30 \\
(100 \%)\end{array}$ & $\begin{array}{l}30 \\
(100 \% \\
)\end{array}$ & $\begin{array}{l}30 \\
(100 \% \\
)\end{array}$ & & & & \\
\hline
\end{tabular}

We used a simplified PONV score similar to that used by Kaja $\mathrm{S}$ et al in demonstrating a reduction in PONV score, probably due to the enhanced analgesia and the opioidsparing effect of TAP block. ${ }^{[32]}$ We found that incidence of PONV and post-operative antiemetic requirement was reduced significantly in Group B and Group C, compared to Group A. Refering to Table 4, we can see that the cumulative PONV score for Group A was $1.8 \pm 1.56$, which was significantly greater than for Group $\mathrm{B}(0.17 \pm 0.38)$ and Group C $(0.13 \pm 0.34)$. In Group A, $46.7 \%$ of patients required anti-emetics, which was significantly greater $(\mathrm{p}<0.05)$ as compared to Group B and Group C, as shown in Figure 6. The results were comparable in Group B and Group $\mathrm{C}$, where none of the patients required anti-emetics at any point of time during 24 hours which was probably due to the better pain relief and reduced opioid consumption in this group of patients. Our findings were similar to the findings of Baaj et al who also reported a reduction in PONV incidence in their study (5\% in TAP group Vs $10.5 \%$ in control group) in patients undergoing caesarean section under spinal anesthesia. ${ }^{[20]}$

Apart from a reduction in pain scores in the mother, a decrease in inpatient sedation is desirable for improving the compliance with post-operative care including mobilisation and communication. Sedation scores used in previous studies lack standardization and differ as per institutional protocols. So we used a simplified AVPU scoring system ${ }^{33}$ which is user friendly and can be assessed even by a trained nurse; for measuring the level of post-operative sedation. We found some degree of sedation (response to verbal commands) in group A in $6.7 \%$ of patients at 10 hours, $13.3 \%$ of patients at 12 hours and $6.7 \%$ of patients at 24 hours post-operatively in comparison to Group B and group $\mathrm{C}$, where none of the patients were found sedated at any point of time (patients were comfortably asleep and easily arousable) probably due to reduced opioid consumption by this group of patients. None of the patients in any group of our study had respiratory depression (respiratory rate $<8$ ) or desaturation $\left(\mathrm{SpO}_{2}<90 \%\right)$. Results similar to our findings were noted by McDonnell JG et al who found $36 \%$ reduction in sedation scores in the TAP block group in patients post CS. ${ }^{[15]}$

Table 4:
\begin{tabular}{|l|l|l|l|l|l|l|}
\hline $\begin{array}{l}\text { Cumulative } \\
\text { score of } \\
\text { PONV }\end{array}$ & $\begin{array}{l}\text { Mean } \\
\pm \text { SD }\end{array}$ & Min - Max & P Value & $\begin{array}{l}\text { Group } \\
\text { A } \\
\text { vs } \\
\text { Group } \\
\text { B }\end{array}$ & $\begin{array}{l}\text { Group } \\
\text { A } \\
\text { vs } \\
\text { Group } \\
\text { C }\end{array}$ & $\begin{array}{l}\text { Group } \\
\text { B } \\
\text { vs } \\
\text { Group } \\
\text { C }\end{array}$ \\
\hline Group A & $\begin{array}{l}1.8 \pm \\
1.56\end{array}$ & $0-5$ & $<0.001^{*}$ & 0.005 & 0.005 & 1.000 \\
& & & & & \\
\hline Group B & $\begin{array}{l}0.17 \pm \\
0.38\end{array}$ & $0-1$ & & & & \\
\hline Group C & $\begin{array}{l}0.13 \pm \\
0.34\end{array}$ & $0-1$ & & & & \\
& & & & & & \\
\hline
\end{tabular}

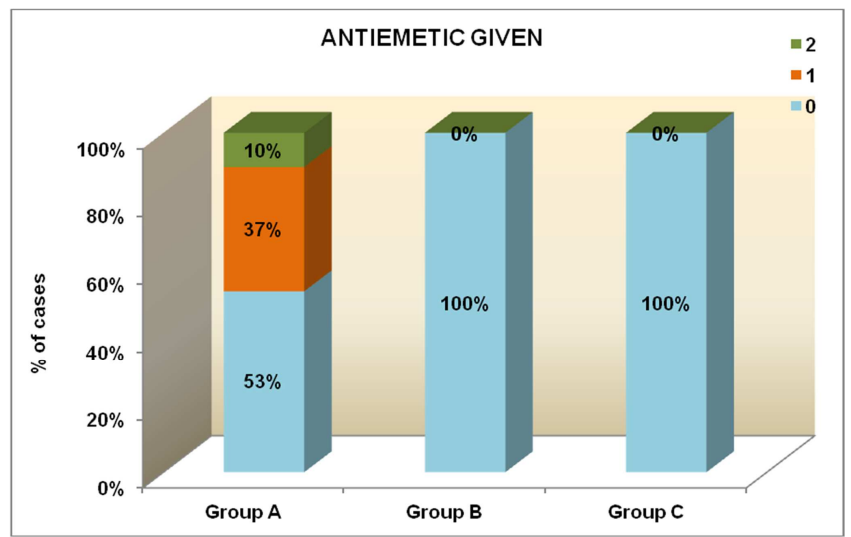

Figure 6:

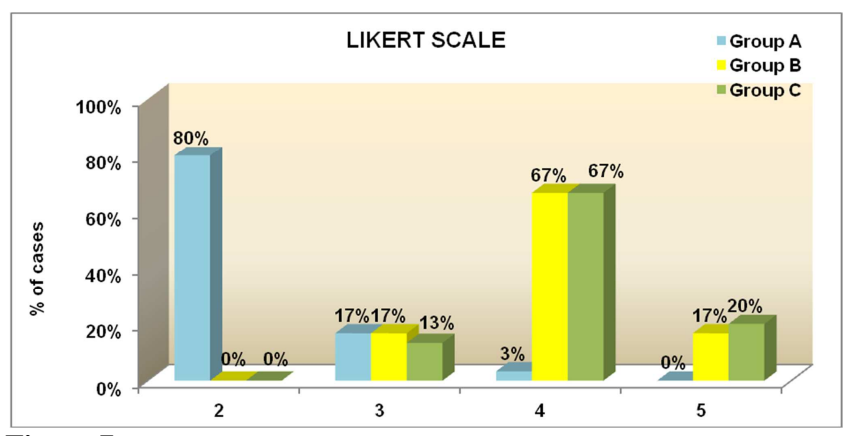

Figure 7:

The results of this study demonstrated that TAP block with $20 \mathrm{ml}$ or $30 \mathrm{ml}$ of $0.2 \%$ Ropivacaine supplemented by IV 
Acetaminophen and PCA fentanyl was more effective in reducing severity of pain and reduced the need of opiod and rescue analgesics during first $24 \mathrm{~h}$ after surgery in patients undergoing cesarean section under spinal anesthesia, compared to TAP block with $15 \mathrm{ml}$ of local anaesthetic. The patients receiving TAP block in these 2 groups also had lower PONV and were less drowsy and more satisfied with their pain management compared to those who recieved TAP block with $15 \mathrm{ml}$ of $0.2 \%$ Ropivacaine.

Significantly more number of patients in group B and C were satisfied with their pain management as they could feed and could care for their new born being pain-free. [Figure 7]

To date, no trials have investigated the effects of local anaesthetic volume, concentration, or dose on block duration, spread, and safety for both single-injection and continuous TAP blocks. While some investigators used a weight-based dose of local anaesthetic, others used a predetermined arbitrary injection volume, the latter being a practice that may increase the risk of local anaesthetic toxicity in patients with low body weight, and in special situations like pregnancy, which is associated with a heightened sensitivity to local anaesthetics and can predispose these patients to local anaesthetic systemic toxicity (LAST). There is increasing evidence that doses local anaesthetics commonly used for bilateral TAP block can reach potentially toxic levels. ${ }^{[10-13,34-37]}$ Various factors like the reduced threshold for toxicity ${ }^{[37]}$, increased concentrations of free drug available due to decreased protein binding, venous distension of inferior vena cava (IVC) and an increased cardiac output leading to increased uptake and distribution of the drug ${ }^{[38,39]}$ together with increased neuronal susceptibility to local anaesthetics can all predispose to LAST in pregnant mothers. ${ }^{[3]}$ Finally, the concomitant use of subarachnoid block could also increase the systemic absorption of the drug due to vasodilation thereby predisposing to systemic toxicity. ${ }^{[40]}$ It would therefore be prudent to use the lowest possible concentration of local anaesthetic necessary to achieve the desired spread for a successful block.

Nevertheless, realizing the limits posed by toxicity, the dose parameters are still subject to 2 conflicting priorities: duration and spread. Although it is logical to assume that the use of higher local anaesthetic doses (and concentrations) in TAP block prolongs the duration of analgesia, TAP block remains a compartmental field block with an extent of dermatomal spread largely dependent on the volume of local anaesthetic injected. ${ }^{[24]}$

Plasma concentrations of Ropivacaine after this block were first reported by Griffiths et al in 2010 ${ }^{[10]}$ In 2012, Torup et al analysed data from 18 patients presenting for abdominopelvic surgery who received TAP block with $20 \mathrm{ml}$ of $0.5 \%$ Ropivacaine on each side. Their study further showed that TAP blocks with bilateral injections of $20 \mathrm{ml}$ ropivacaine $0.5 \% \mathrm{w} / \mathrm{v}$ gave rise to potentially toxic peak blood concentrations of total ropivacaine in one-third of the patients. ${ }^{[11]}$ There is also one report of seizures and another of cardiac arrest from local anaesthetic toxicity after TAP block. ${ }^{[12,13,33]}$

Although ultrasound allows real time needle visualisation, it does not guarantee that the tip of the needle is in the plane and partial intramuscular or intraperitoneal injection may still occur and lead to toxicity even though the total dose given is well within permissible limits, as observed by Jadon et al. ${ }^{13}$ To minimise such complications, measures like decreased drug concentrations $(0.2 \%$ ropivacaine) and visualisation of the needle tip at all times during the procedure to prevent inadvertent intramuscular/intraperitoneal injection have been incorporated into the study protocol. Therefore a consensus needs to be developed regarding the safe dose and concentration of local anaesthetic solution to limit the systemic toxic complications of the block without affecting its analgesic efficacy. And the question that still remains unsolved is 'Can we make the plasma levels of local anaesthetic after TAP block lower, safer or better?'.

By comparing three different volumes of Ropivacaine we tried to solve the decade long query, 'What is the optimal volume of local anaesthetic to be used for TAP block in Caesarean section?' We found an increased efficacy by increasing the volume of Ropivacaine from $15 \mathrm{ml}$ bilaterally to $20 \mathrm{ml}$ and $30 \mathrm{ml}$ bilaterally. Increasing the volume of Ropivacaine from $20 \mathrm{ml}$ to $30 \mathrm{ml}$ bilaterally did not lead to any significant advantage in terms of reduced VAS score, PONV scores, opioid consumption, sedation score or patient satisfaction. We recommend $20 \mathrm{ml}$ of $0.2 \%$ Ropivacaine as the safest dose to be used in TAP block in post caesarean section patients as $30 \mathrm{ml}$ volume might lead to toxicity in the mother due to their heightened intrinsic sensitivity to local anaesthetics in pregnancy and also offers no significant advantage in terms of reduction in VAS scores or opioid consumption.

However our study was not without limitations. Firstly although we did not encounter block-related complication in any patient, our sample size was not enough to assess the safety. While randomised controlled trials demonstrate the analgesic efficacy of TAP block, they are not largely powered to identify rare complications of the block. Hence larger safety trials are needed.Although the block technique was the same, the blocks in our study were performed by a different anaesthetist each time which probably resulted in some inter-individual technique variability. The dermatomal spread could not be assessed in our patients as the block was given in the immediate post-operative period when patients still had sensory loss due to the spinal anaesthetic. The analgesic efficacy of TAP block has been demonstrated for upto 48 hours in previous studies, while we only assessed patients for 24 hours. All patients were given IV Acetaminophen $8^{\text {th }}$ hourly as per hospital protocol, which could have been synergistic in reducing pain intensity along with opioids and TAP block. This may have been a confounding factor in calculating the total dose of rescue analgesic.

To conclude, we can safely recommend $20 \mathrm{ml}$ of $0.2 \%$ Ropivacaine for use in TAP block for Cesarean section patients. As TAP block results in significant reduction in opioid consumption and opioid related side-effects which facilitates better maternal-infant bonding and enables the mother to nurse the new-born more efficiently, it is recommended for all patients undergoing cesarean section under spinal anesthesia, in the absence of long acting intrathecal morphine. As use of ultrasound results in enhanced safety and allows accurate placement of the drug within the TAP, USG guided TAP block is therefore recommended for all patients, especially in the setting of 
pregnancy where maternal weight gain may make blind technique challenging . The use of TAP catheters can further prolong the duration of analgesia, and should be preferred over giving additional volume or higher concentrations of local anesthetic, particularly during pregnancy which is associated with heightened sensitivity to local anaesthetics.

\section{Conclusion}

We concluded that though increasing the volume of local anaesthetic from $15 \mathrm{ml}$ bilaterally to $20 \mathrm{ml}$ bilaterally resulted in increased duration and quality of analgesia, further increase to $30 \mathrm{ml}$ bilaterally offered no significant advantage in terms of reduction in VAS scores or opioid consumption.

\section{References}

1. Leung AY. Postoperative pain management in obstetric anesthesia New challenges and solutions. J Clin Anesth. 2004;16:57-65.

2. Gadsden J, Hart S, Santos AC. Post-cesarean delivery analgesia. Anesth Analg. 2005;101:S62-9.

3. Urbanczae L. Transverse abdominis plane block. Anesth Intensive Ther. 2009;35:137-41.

4. Belavy D, Cowlishaw PJ, Howes M, Phillips F. Ultrasound-guided transversus abdominis plane block for analgesia after Caesarean delivery. Br J Anaesth. 2009;1:726-30.

5. Tan TT, Teoh WH, Woo DC, Ocampo CE, Shah MK, Sia AT. A randomised trial of the analgesic efficacy of ultrasound-guided transversus abdominis plane block after caesarean delivery under general anesthesia. Eur J Anaesthesiol. 2012;29:88-94.

6. Rafi AN. Abdominal field block: A new approach via the lumbar triangle. Anesthesia. 2001;56:1024-6.

7. McDonnell JG, O'Donnell B, Curley G, Heffernan A, Power C, Laffey JG. The analgesic efficacy of transversus abdominis plane block after abdominal surgery: A prospective randomized controlled trial. Anesth Analg. 2007;104:193-7.

8. Rozen WM, Tran TM, Ashton MW, Barrington MJ, Ivanusic JJ, Taylor GI. Refining the course of the thoracolumbar nerves: A new understanding of the innervation of the anterior abdominal wall. Clin Anat. 2008:21:325-33.

9. Griffiths JD , Le NV, Grant S, Bjorksten A, Hebbard P, Royse C. Symptomatic local anaesthetic toxicity and plasma ropivacaine concentrations after transversus abdominis plane block for Caesarean section. Br J Anaesth 2013;110:996-1000.

10. 10.Griffiths JD, Barron FA, Grant S, Bjorksten AR, Hebbard P, Royse CF. Plasma ropivacaine concentrations after ultrasound-guided transversus abdominis plane block. Br J Anaesth 2010;105:853-56.

11. Torup $\mathrm{H}^{1}$, Mitchell AU, Breindahl T, Hansen EG, Rosenberg J, Moller AM. Potentially toxic concentrations in blood of total ropivacaine after bilateral transversus abdominis plane blocks; a pharmacokinetic study. Eur J Anaesthesiol 2012;29:235-8.

12. Richeb P, Naidu RK, Liu SK, Bollag LA, Landau R. A Case Report of Seizures following Transversus Abdominis Plane (TAP) Blocks in a Patient with Acute Fatty Liver of Pregnancy. SOAP 2010;227.

13. Jadon A, Jain P, Chakraborty S, Motaka M, Parida SS, Sinha N. Role of ultrasound guided transversus abdominis plane block as a component of multimodal analgesic regimen for lower segment caesarean section: a randomized double blind clinical study. BMC Anesthesiology (2018) 18:53

14. Petersen PL, Mathiesen O, Torup H, Dahl JB. The transversus abdominis plane block: A valuable option for postoperative analgesia? A topical review. Acta Anaesthesiol Scand. 2010;54:529-35.

15. McDonnell JG, Curley G, Carney J, Benton A, Costello J, Maharaj $\mathrm{CH}$, et al. The analgesic efficacy of transversus abdominis plane block after cesarean delivery: A randomized controlled trial. Anesth Analg. 2008;106:186-91

16. White PF. The changing role of non-opioid analgesic techniques in the management of postoperative pain. Anesth Analg. 2005;101:S5-22.

17. Mukhtar K. Transversus Abdominis Plane (TAP) Block. The Journal Of New York School Of Regional Anesthesia. 2009;12:28-33.
18. 18.Niraj G, Searle A, Mathews M, Misra V, Baban M, Kiani S, et al. Analgesic efficacy of ultrasound-guided transversus abdominis plane block in patients undergoing open appendicectomy. $\mathrm{Br} \mathrm{J}$ Anaesth. 2009;103:601-5.

19. El-Dawlatly AA, Turkistani A, Kettner SC, Machata AM, Delvi MB, Thallaj A, et al. Ultrasound-guided transversus abdominis plane block: Description of a new technique and comparison with conventional systemic analgesia during laparoscopic cholecystectomy. Br J Anaesth. 2009;102:763-7.

20. Baaj JM, Alsatli RA, Majaj HA, Babay ZA, Thallaj AK. Efficacy of ultrasound-guided transversus abdominis plane (TAP) block for postcesarean section delivery analgesia - A double-blind, placebocontrolled, randomized study. Middle East J Anaesthesiol. 2010;20:821-6.

21. Sriramkes B, Sahoo N, Panigrahi S. Analgesic efficacy of ultrasound guided transverse abdominis plane block following cesarean section. Int J Perioper Ultrasound Appl Technol. 2012;1:5-8.

22. Eslamian L, Jalili Z, Jamal A, Marsoosi V, Movafegh A. Transversus abdominis plane block reduces postoperative pain intensity and analgesic consumption in elective cesarean delivery under general anesthesia. J Anesth. 2012;26:334-8.

23. Mankikar MG, Sardesai SP, Ghodki PS. Ultrasoundguided transversus abdominis plane block for postoperative analgesia in patients undergoing caesarean section. Indian J Anesth. 2016;60:253-7

24. Abdallah FW, Halpern SH, Margarido CB. Transversus abdominis plane block for postoperative analgesia after Caesarean delivery performed under spinal anesthesia? A systematic review and metaanalysis. Br J Anaesth. 2012;109:679-87.

25. Costello JF, Moore AR, Wieczorek PM, Macarthur AJ, Balki M, Carvalho JC. The transversus abdominis plane block, when used as part of a multimodal regimen inclusive of intrathecal morphine, does not improve analgesia after cesarean delivery. Reg Anesth Pain Med. 2009;34:586-9.

26. McMorrow RC, Ni Mhuircheartaigh RJ, Ahmed KA, Aslani A, Ng SC, Conrick-Martin I, et al. Comparison of transversus abdominis plane block vs spinal morphine for pain relief after Caesarean section. Br J Anaesth. 2011;106:706-12.

27. Srivastava U, Verma S, Singh TK, Gupta A, Saxsena A, Jagar KD, et al. Efficacy of trans abdominis plane block for post cesarean delivery analgesia: A doubleblind, randomized trial. Saudi J Anaesth 2015;9:298302.

28. Cansiz KH, Yedekci AE, Sen H, Ozkan S, Dagli G. The effect of ultrasound guided transversus abdominis plane block for cesarean delivery on postoperative analgesic consumption. Gulhane Med J 2015;57:1214.

29. Chansoria S, Hingwe S, Sethi A, Singh R. Evaluation of transversus abdominis plane block for analgesia after caesarean section. J Recent Adv Pain 2015;1:137

30. 30.Verstraete S, Velde MV. Post-cesarean section analgesia. Acta Anaesth Belg 2012;63:147-67.

31. 31.Fields HL. Pain: mechanisms and management. In: Rice A, Justins D, Newton-John T, Howard RF, Miaskowski CA, editors. Clinical Pain Management. 2nd ed. United States Of America: Taylor and Francis Group; 2008. P 327-571.

32. 32.Kaja S, Giri RS, Tugave DV, Iqbal M. A randomized clinical trial comparing the efficacy and safety of ramosetron versus ondansetron in patients undergoing abdominal surgery under general anesthesia. Saudi J Anaesth 2014:8:59-63.

33. 33.Liddle C. Postoperative care 1: principles of monitoring postoperative patients. Nursing Times 2013;109:24-6

34. Scherrer V, Compère V, Loisel C, Dureuil B. Cardiac arrest from local anesthetic toxicity after a field block and transversus abdominis plane block: a consequence of miscommunication between the anesthesiologist and surgeon. Anesth Analg Case Reports 2013.

35. Griffiths JD, Le NV, Grant S, Bjorksten A, Hebbard P, Royse C. Symptomatic local anaesthetic toxicity and plasma ropivacaine concentrations after transversus abdominis plane block for caesarean section. Br J Anaesth. 2013;110:996 -1000.

36. Knudsen K, Beckman Suurkula M, Blomberg S, Sjovall J, Edvardsson N. Central nervous and cardiovascular effects of i.V. Infusions of ropivacaine, bupivacaine and placebo in volunteers. Br J Anaesth. 1997;78:507 -14.

37. Santos AC, DeArmas PI. Systemic toxicity of levobupivacaine, bupivacaine, and ropivacaine during continuous intravenous infusion to nonpregnant and pregnant ewes. Anesthesiol. 2001;95:1256 -64.

38. Santos AC, Pedersen H, Harmon TW, et al. Does pregnancy alter the 
Malik et al: Camparisan of Different Valumes of Lacal Anacsthetic ta Determine Optimal Valume ta Be Used in TAP Black for Past Caesarean Sectian Analgesia

systemic toxicity of local anesthetics? Anesthesiol. 1989;70:991 -5.

39. Tsen LC, Tarshis J, Denson DD, Osathanondh R, Datta S, Bader AM.

Measurements of maternal protein binding of bupivacaine throughout pregnancy. Anesth Analg. 1999;89:965 -8
40. Chandon M, Bonnet A, Burg Y, Barnichon C, DesMesnards-Smaja V, Sitbon B, et al. Ultrasound guided transversus abdominis plane block versus continuous wound infusion for post-caesarean analgesia: a randomized trial. PLoS One. 2014;9(8):e103971.

Copyright: ( $)$ the author(s), publisher. Academia Anesthesiologica International is an Official Publication of "Society for Health Care \& Research Development". It is an open-access article distributed under the terms of the Creative Commons Attribution Non-Commercial License, which permits unrestricted non-commercial use, distribution, and reproduction in any medium, provided the original work is properly cited.

How to cite this article: Malik S, Malik S, Karim W, Chabda R. Comparison of Different Volumes of Local Anaesthetic to Determine Optimal Volume to Be Used In TAP Block for Post Caesarean Section Analgesia. Acad. Anesthesiol. Int. 2019;4(2):226-233.

DOI: dx.doi.org/10.21276/aan.2019.4.2.52

Source of Support: Nil, Conflict of Interest: None declared. 